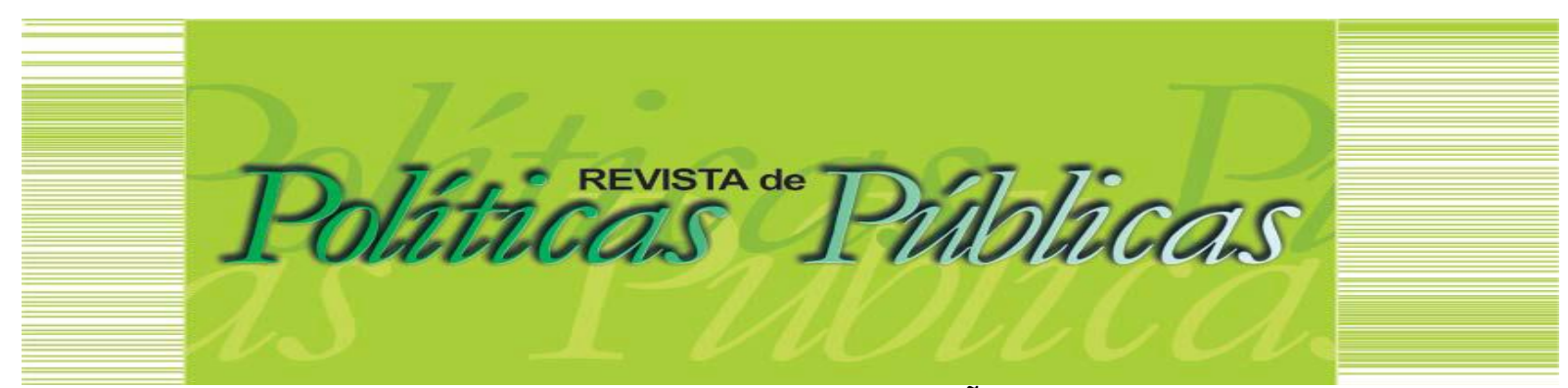

\title{
SUJEITOS COLETIVOS NA ESTEIRA DA GLOBALIZAÇÃO: a voz da classe trabalhadora brasileira
}

\author{
Pollyanna de Souza Carvalho ${ }^{1}$
}

\begin{abstract}
Resumo
Oriundo de pesquisa bibliográfica, o estudo discute os conflitos e as lutas sociais travadas pela classe trabalhadora no Brasil pós-1970, demonstrando um contexto marcado pelo autoritarismo, violência, repressão, expropriações urbanas, injustiças sociais e militarização das ações coletivas, essencialmente após a reestruturação produtiva e advento de uma economia financeirizada, seguida pelas mercantilizações, privatizações e desmonte dos direitos de cidadania. Por outro lado, salienta a potencialidade de ressignificação dos itinerários de vida pela classe trabalhadora, movimentos sociais e ações coletivas, além do uso dos espaços públicos para debates, ampliação de agendas públicas e negociação com o poder público, para não reproduzir o movimento de subalternidade e expropriação dos grupos da política e participação, dos serviços e da socialização da riqueza produzida.
\end{abstract}

Palavras-chave: Capitalismo contemporâneo. Brasil. Estado. Lutas Sociais. Direitos.

\section{COLLECTIVE SUBJECTS ON THE LINE OF GLOBALIZATION: the voice of Brazilian working class}

\section{Abstract}

From bibliographic research, the study debates about the conflicts and social struggles fought by the working class in the Brazil post-1970s, demonstrating a scenario marked by authoritarianism, violence, repression, urban expropriations, social injustices and the militarization of collective actions, especially after the productive restructuring and the advent of a financial economy, followed by mercantilizations, privatizations and dismantling of citizenship rights. On the other side, shows the potentiality of resignifying life paths by the working class, social movements and collective actions, in addition to the use of public spaces for debates, expansion of public schedule and negotiation with public power, to not to reproduce the movement of subordination and expropriation of groups of politics and participation, services and the socialization of wealth produced.

Keywords: Contemporary capitalism. Brazil. State. Social Struggles. Rights.

Artigo recebido em: 10/04/2020 Aprovado em: 13/10/2020

DOI: http://dx.doi.org/10.18764/2178-2865.v24n2p703-720

1 Graduada em Serviço Social pela Universidade Federal Fluminense (UFF). Mestranda em Serviço Social pela Universidade Federal do Rio de Janeiro (ESS/UFRJ). Integra o NUFSTEV-UFF (Núcleo de Pesquisa em Famílias, Sujeitos Sociais e Territórios Vulneráveis) e o LOCUSS-UFRJ (Núcleo de Pesquisa e Extensão Políticas Públicas, Território, Lutas Sociais e Serviço Social). E-mail: pollyannacecf@gmail.com 


\section{INTRODUÇÃO}

O estudo versa sobre os conflitos e as lutas sociais travadas pela classe trabalhadora no Brasil pós-1970, demonstrando um contexto marcado pelo autoritarismo, violência, repressão, injustiças sociais, expropriações urbanas e militarização das ações coletivas, essencialmente após a reestruturação produtiva e advento de uma economia financeirizada, seguida pelas mercantilizações, privatizações e desmonte dos direitos de cidadania. Por outro lado, salienta a potencialidade de ressignificação dos itinerários de vida pela classe trabalhadora, movimentos sociais ${ }^{1}$ e ações coletivas, além do uso dos espaços públicos para debates, ampliação de agendas públicas e negociação com o poder público.

Para atingir o objetivo proposto, com eixos estruturantes como lutas sociais e Estado, a metodologia empregada foi a pesquisa bibliográfica a partir dos pensamentos de Antunes (2010), Behring (2008, 2010), Behring e Boschetti (2011), Brettas (2020), Coutinho (2006), Dagnino (2004), Duriguetto e Montaño (2011), Gohn (1997, 2000, 2003), Lowy (1995), Maricato (2013), Netto (2011), Pereira (2010), Raichelis (2000, 2006), Sader (2001), Simionatto (2009), Telles (1994), Vainer (2013), entre outros autores.

Após a crise estrutural do capital na década de 1970 nos países centrais, percebe-se que este contexto incidiu mais gravemente nos países periféricos nos anos seguintes, como é o caso brasileiro. Este país passou a recriar as heranças da própria formação sócio-histórica como 0 autoritarismo, patrimonialismo, racismo institucional e relações atrasadas sob o manto da pseudoigualdade jurídica, já que se sobrevive numa sociedade de classes.

Todavia, ante as expropriações enveredadas pela financeirização da economia e de seus agentes rentistas, a classe trabalhadora esteve ativa e propositiva na luta por direitos sociais, em especial após o período marcado pela "autocracia burguesa" (NETTO, 2011). Vis-à-vis, diversos atores insurgiram em cena para pressionar o Estado e cobrar por melhores oportunidades de serviços e políticas públicas, como os movimentos sociais, sindicais, estudantis, do campo, pelo direito à cidade, entre outros.

Essa forma de organização das ações coletivas foi uma oportunidade para 0 estabelecimento das agendas de lutas, de demandas e até mesmo de apoios, redes e parcerias tanto no âmbito nacional quanto no plano internacional, essencialmente em relação aos movimentos sociais mais organizados. A crise do capital que assolava mais os países periféricos também se fazia presente nos países centrais, demonstrando que a acumulação angariava lucratividade com a introdução de uma nova morfologia do trabalho; com o enxugamento das respostas estatais na área social; e em seu 
espraiamento em todas as áreas da sociedade, subordinando os trabalhadores, cidades, formas de existência e cultura. Por isso, a defesa dos movimentos sociais e das ações coletivas de suas agendas, planos, identidades e direitos, para a não reprodução do movimento de subalternidade e expropriação dos grupos dos espaços públicos, dos serviços e da socialização da riqueza produzida.

A cidade, portanto, não só é o espaço da produção e reprodução da classe trabalhadora, como é o berço da valorização do capital, sobretudo na onda da financeirização e especulação dos bens e obras públicas. Os interesses na cidade são diversos entre os atores sociais, e este processo culmina em conflitos e mobilizações coletivas contra as expropriações e desestruturação das formas de vida, de território e cultura.

No Brasil, após a década de 1990 em diante, percebeu-se a expansão das políticas neoliberais e 0 ajuste fiscal incidindo nas condições de vida da população, assim como 0 arrocho salarial e a precarização das condições de trabalho e sobrevivência. Este caso não impossibilitou 0 nascimento de outros conflitos em função do aumento desenfreado da exploração dos ambientes, espaços públicos, condições de trabalho e da mais-valia dos trabalhadores. A isso se soma a desconstrução dos princípios constitucionais de cidadania assegurados na Constituição Federal de 1988 (CF/88).

Agir contra o sistema capitalista e o ideário neoliberal é se confrontar com o Estado, na concepção gramsciana, o qual funciona por meio da difusão de consentimento e coerção, "educando o consenso" e o controlando por meio dos aparelhos privados de hegemonia, que disseminam o senso comum $^{2}$ e criam obstáculos para a participação social e política dos sujeitos na sociedade (SIMIONATTO, 2009). Segundo Raichelis (2006, p. 20), não se pode desconsiderar que o pilar central para a efetivação da cidadania é a mediação dos conflitos pela sociedade política, negociação e luta pela hegemonia. Até porque a esfera pública significa espaço de conflitos e lutas sociais entre divergentes projetos, mesmo que estejam em curso, entretanto, o aumento das demandas sociais não atendidas, a fragmentação da sociedade civil e a carência de projetos coletivos são capazes de produzir novas coletividades e agregações sociais.

O debate que se segue abordará as lutas sociais que se inscreveram no Brasil pós-1970, suas demandas e opositores políticos e econômicos, em um cenário marcado por reivindicações de direitos, serviços públicos, participação e cidadania. Diversos sujeitos se mobilizaram ao longo dos anos, e isso não quer dizer que suas pautas foram esquecidas, pelo contrário, elas permanecem vivas até hoje. Os conflitos sociais contra o autoritarismo no país e exclusão não são recentes, mas seculares, o que demonstra os profundos descasos e desigualdades com a população, mormente os trabalhadores e grupos subalternos. 
Ao longo da discussão, observa-se como as lutas são mecanismos, ante a consciência e organização política da classe trabalhadora, para o alcance de um horizonte democrático. Fato é que sem tais pressões sociais nem a CF/88, os espaços decisórios e políticas urbanas seriam conquistados. O neoliberalismo pode ter sido capaz de fragmentar a união dos trabalhadores e sindicatos, mas não derruiu totalmente a luta e consciência de classe. Isso reforça a ideia de como um novo horizonte pode ser alçado via democracia, justiça social e contra-hegemonia.

\section{CONFLITOS E LUTAS SOCIAIS NO CONTEXTO BRASILEIRO PÓS-1970}

Ao resgatar as marcas sócio-históricas desde os tempos da Colônia (séc. XVI-XIX), Gohn (2000, p. 15-16) notou que várias lutas e movimentos sociais se adentraram na sociedade em oposição à dominação, exploração econômica e exclusão social. Os atores, em sua maioria, eram compostos por negros escravos e pela plebe, oriundos das camadas empobrecidas e livres. Com o passar dos séculos, a partir do advento da República (1889-1930) e com a substituição da mão de obra escrava pela assalariada, viu-se um mercado de trabalho formado pelos imigrantes e, posteriormente, no ano de 1930 com a industrialização em curso, estruturou-se o proletariado urbano, emergindo organizações de luta e resistência por parte da classe trabalhadora (GOHN, 2000). Essas lutas marcaram todo 0 século XX, incluindo o período da Ditadura Civil-Militar de 1964.

Após a Segunda Guerra Mundial, o governo brasileiro realizou a abertura do país ao capital estrangeiro - desde a década de 1940, em especial no ano de 1955 com o governo de Juscelino Kubitschek -, apoiando novas relações de parcerias internacionais e a ampliação da perspectiva de modernização econômica à custa do trabalhador. Foram muitas lutas e conflitos envolvendo os trabalhadores urbanos e rurais. A denúncia se direcionava à piora das condições de vida e os processos de espoliação, especialmente a partir do Golpe Civil-Militar de 1964, sob as ações da "autocracia burguesa", cujo termo foi cunhado por Netto (2011).

Como diz Raichelis (2000), inserido na dinâmica brasileira esteve a simbiose entre 0 público e o privado, a intensificação da política do favor desenhada pelo clientelismo político e ainda a construção de um Estado mini-max: mini em relação ao trabalho e máximo ligado ao capital. Esse movimento, conhecido como modernização conservadora, se expande atualmente através do autoritarismo, abuso de poder e distanciamento da cidadania, essencialmente nos países de industrialização tardia. 
No curso desses processos deletérios para a classe trabalhadora, foram vários sujeitos sociais e conflitos que travaram um leque de oposição à acumulação e valorização do capital. Não seria diferente desta lógica que as lutas sociais contra o sistema capitalista (RAICHELIS, 2006) transformaram a "questão social"3 em uma questão pública e política, em um deslocamento do âmbito privado das relações entre capital e trabalho, para o âmbito público. Inclusive, requerendo-se ações do Estado na identificação de novos protagonistas sociais como sujeitos de direitos e deveres, e no provimento do acesso a bens e serviços públicos via políticas sociais.

Comprometidos com esse debate, Duriguetto e Montaño (2011) explanam que, no caso brasileiro, a ampliação dos movimentos sociais ocorreu num cenário de mutações na economia e expropriação das classes subalternas. 0 padrão de desenvolvimento econômico-social adotado pela ditadura (1964-1985) aprofundou a dependência e subordinação do país à nova ordem do capital internacional, culminando no aumento da desigualdade social. Não por acaso, o período do milagre econômico (1968-1973), apesar de expandir o capitalismo brasileiro, resultou no endividamento externo e sua crise, onde os trabalhadores foram mais penalizados no que tange ao arrocho salarial e desemprego. Foi no início desse ano, também, a implementação do Ato Institucional $n^{0} 5$ (Al-5), em 1968, o qual exercia coerção, autoritarismo e pressão aos inimigos do regime, tendo dificultado a expressão dos movimentos sociais, sobretudo até o ano de 1969 (GOHN, 2000, p. 18).

Mais tarde, presenciou-se nos países centrais uma aguda crise que afetou diretamente 0 mundo do trabalho e, a posteriori, interferiu no desenvolvimento social dos países periféricos, como foi o caso do Brasil. Segundo Antunes (2010), o sistema capitalista, para sobreviver aos impactos da crise, se reestruturou produtivamente para retomar aos seus ciclos, prejudicando a classe trabalhadora materialmente (sua forma de viver e ser) e subjetivamente (moral e valores), o que tem tornado essa mesma classe mais heterogênea, individualista, fragmentada e desunida. Além do mais, ocorreu a diminuição dos trabalhadores fabris, precarizou-se o trabalho 4 e suprimiu-se a mão de obra jovem e idosa. Para ele "intensificaram-se as transformações no próprio processo produtivo, por meio do avanço tecnológico, da constituição das formas de acumulação flexível [...], onde se destaca para 0 capital especialmente o toyotismo ou o modelo japonês" (ANTUNES, 2010, p. 183).

O conjunto desses processos societários atingiu, em cheio, as periferias do capitalismo, causando mais degradação da condição de vida dos trabalhadores. Expressa Löwy (1995) que a "teoria do desenvolvimento desigual e combinado" é importante para se refletir sobre o imperialismo e sua influência nos países de capitalismo periférico. $O$ autor afirma que a referida teoria consegue explicar os antagonismos existentes no plano econômico e social dos países periféricos ou dominados pelo imperialismo, que tem a tarefa de se expandir nas regiões mais pobres do mundo. 
Nessa direção, ao mesmo tempo em que ocorre a expansão dos mercados capitalistas, as sociedades periféricas e que tiveram uma industrialização tardia - como o Brasil - recebem exigências a adotar dos países centrais, que são os aspectos modernos e/ou avançados. Sendo que, devido a suas raízes de formação social e econômica, este desenvolvimento se torna irregular, complexo e combinado, refletindo a "desigualdade do ritmo". Tal desigualdade se refere a uma lei geral do processo da história dos países, impreterivelmente dos periféricos e de seus destinos na mundialização do capital (LOWY, 1995).

Apesar de se encontrar na periferia do capital, o Brasil, após a crise internacional do petróleo, foi palco de articulação de resistências ao regime ditatorial (GOHN, 2000, p. 18-19). Sader (2001) acrescenta que surgiram indagações a respeito das potencialidades dos sujeitos sociais, que apenas poderiam se desenvolver fora da institucionalidade. Assim, no final da década de 1970, o que se observava era a emergência de movimentos operários e populares, com traços de autonomia e contestação à ordem instaurada. Era o "novo sindicalismo" que se propunha de forma independente do Estado e dos partidos; eram os "novos movimentos de bairros" que se construíram em um processo de autoorganização para a luta por direitos, não os trocando pelos favores; era a irrupção de uma "nova sociabilidade" em associações comunitárias, com marcas de solidariedade e ajuda; eram os "novos movimentos sociais" 5 que politizavam lugares antes silenciados no âmbito privado (SADER, 2001).

Contabilizam-se, ainda, os conflitos sociais, como indicam Duriguetto e Montaño (2011), contra o processo de retração do atendimento às necessidades sociais dos trabalhadores e segmentos sociais. Para tal, sobressaíram-se no cenário os movimentos sindicais, do campo e estudantil na luta direcionada a um projeto de desenvolvimento nacional autônomo, contra a exclusão, a favor da democratização do país e do Estado. Como exemplo desses atores, pode-se mencionar a União Nacional de Estudantes (UNE), os Centros Populares de Cultura (CPCs), os movimentos católicos estudantis, secundaristas e do seio acadêmico, relacionados à esquerda como a Juventude Universitária Católica (JUC) e a Juventude Operária Católica (JAC).

Neste ínterim, ao explorar a trajetória dos movimentos populares em São Paulo, nos anos de 1970 e 1980, como o movimento do clube das mães, o Movimento do Custo de Vida (MCV) e a Oposição Sindical Metalúrgica, Sader (2001, p. 10) percebeu que esses atores estavam se constituindo em um novo sujeito social e histórico, na medida em que portavam novos discursos e práticas. Isso se explica porque esse novo personagem era criado pelos próprios movimentos sociais populares, no sentido da existência de um sujeito coletivo e descentralizado, esvaziado de traços individuais. Eles efetuaram uma espécie de alargamento do espaço da política ao encarar a "velha política" ainda dominante no sistema do Estado, resistiram à política historicamente instituída e politizaram questões 
do cotidiano em relação aos espaços de trabalho e a moradia, juntamente na interação com outros sujeitos sociais (SADER, 2001, p. 20-21).

Não ficam de fora os conflitos sociais dos moradores de periferias e as lutas contra a violência urbana nas cidades. De acordo com Gohn (2003, p. 22), desde o período supracitado, estava atuando o movimento contra a violência urbana em bairros, o que demonstrava a solicitação da sociedade civil na área da segurança pública e na proteção à vida. Sendo movimentos focalizados, eles emergem de grupos e ações localizadas, motivados por perdas de parentes, bem como passam a produzir redes e a mobilizar as associações dos bairros (GOHN, 2003).

Neste contributo, leva-se em conta a luta pela moradia dos moradores em situação de rua, assim como, a luta dos ambientalistas pela preservação dos equipamentos e serviços coletivos nas cidades (GOHN, 2003).

No rol da década de 1980, novos modelos de movimentos foram tecidos, como profere Gohn (1997, p. 285), oriundos da conjuntura político-econômica do Brasil. Foram movimentos que divergiam tanto dos movimentos sociais clássicos - como o movimento operário - bem como dos "novos" movimentos sociais que emergiram em 1970, populares e não-populares. Isto é, foram os movimentos dos desempregados e das Diretas Já que se definiam na área da carência do trabalho e na luta pela alteração do regime político.

Nesse fluxo temporal, demonstra Vainer (2013) que os movimentos operários e urbanos transpareciam traduzir politicamente os antagonismos da rápida modernização. Diante disso, para 0 autor, o Movimento de Trabalhadores Rurais Sem Terra (MST), o Movimento de Atingidos por Barragens (MAB) e a resistência de populações tradicionais contra o desmonte de seus meios e modo de vida, se apossaram do palco da arena política popular, além das lutas urbanas como o Movimento Passe Livre, o Movimento dos Trabalhadores Sem Teto, da Central de Movimento Populares, 0 Movimento Nacional de Meninos e Meninas de Rua e o Movimento Nacional de Luta pela Moradia.

Adiciona Gohn (2003, p. 20) que são inegáveis as pressões organizadas objetivando direitos sociais novos, os quais foram inseridos nas leis da nova Constituição do Brasil de 1988 $\mathrm{CF} / 88$, sendo construída pelas lutas da classe trabalhadora na forma de profissionais, ativistas, militantes, movimentos sociais ${ }^{6}$, estudantes e outros segmentos sociais, engajados em fazer da política e da sociedade um espaço democrático e inclusivo, diferentemente dos princípios coercitivos e repressivos praticados pelos representantes políticos ditatoriais.

Isso se explica uma vez que a passagem do período ditatorial no Brasil foi uma mistura de autoritarismo e implementação de políticas sociais, com a finalidade de garantir a exploração de maisvalia dos trabalhadores para o capital internacional, desencadeando a radicalização das expressões da 
questão social. Ao longo dos anos, tal regime se tornou insustentável devido à forte concentração de coerção estatal e de seus representantes, de violência e mortes de militantes da época, além de dívidas públicas e déficits orçamentários. Frente a isso, desencadeou-se um espaço de emergência dos movimentos sociais, ativistas e demais segmentos da classe trabalhadora para instaurar um novo pacto social baseado na democracia. Este processo de lutas, pressão e ações coletivas, como forma de inscrever uma agenda de reinvindicações e demandas públicas, segundo Dagnino (2004), consagrou o princípio de participação da sociedade civil e a constituição de espaços públicos, como os Conselhos Gestores de Políticas Públicas e Orçamentos Participativos via CF/88.

De fato, Telles (1994) também expressa que nesse cenário surgiram sujeitos políticos, hoje, notados como interlocutores no jogo político nacional. Os movimentos sociais, sindicatos e associações civis traçaram estratégias à reestruturação conservadora, para o reconhecimento dos direitos de cidadania, conflitos e ressonância às demandas sociais, seguido do papel de negociação e deliberação de políticas. Logo, a perspectiva de noção pública significou "uma noção plural e descentrada, capaz de traduzir a diversidade e complexidade da sociedade, rompendo, por isso mesmo, com sua versão autoritária, solidamente enraizada na história política do país [...]" (TELLES, 1994, p. 13).

Assim, houve a necessidade da "nova cidadania" elaborada pelos movimentos sociais, os quais já vinham se organizando desde o ano de 1970 em torno de demandas como acesso aos direitos, serviços urbanos, defesa de questões de gênero, raça e etnia, bem como a luta pelos direitos humanos, como protesto ao regime ditatorial. Os movimentos e ações coletivas visavam construir resistência para o retorno da democracia e da transformação social, sob o signo de cultura e política. A "nova cidadania" deveria não estar apenas dentro dos limites das relações com o Estado e sujeitos sociais, mas ser estabelecida no interior da sociedade civil, como um traço das relações sociais existentes entre os indivíduos (DAGNINO, 2004, p. 153-154).

Nesse plano, Coutinho (2006) afirma que o Brasil após o término da ditadura se tornou uma sociedade do tipo "ocidental", estando o Estado e a sociedade civil numa relação justa, sob o viés de que a sociedade civil estava forte e articulada, essencialmente nos meandros do avanço neoliberal no país. Este avanço passou a desenhar dois tipos de propostas para a redefinição do Estado: a primeira de origem liberal, corporativista e burguesa; e, a segunda, de caráter democrática, alinhada à esfera pública de direitos e socialização da política.

A primeira proposta de redefinição estatal, de cunho liberal, começa a ter sentido a partir do desmonte dos princípios democráticos da CF/88, com o andamento da contrarreforma do Estado (BEHRING; BOSCHETTI, 2011). A isso se somam as transformações no trâmite de uma onda 
liberalizante internacional, que retraía tudo o que era social e público. As forças conservadoras do Brasil, que atuaram junto ao regime da ditadura civil e militar e conseguiram se integrar ao centro de poder depois da redemocratização do país, não se alinharam ao conteúdo progressista da Constituição. Ao longo do ano de 1990, perceberam-se os ataques conservadores ancorados na hegemonia neoliberal durante o governo Collor de Mello (1990), em antagonismo aos avanços constitucionais (PEREIRA, 2010).

Na mesma linha, Francisco de Oliveira (1995) acentua que no âmbito neoliberal o governo de Collor foi o ápice da má distribuição de renda e depredação de todas as políticas sociais constituídas. No aparato da macroeconomia, Behring (2008) sobressai que se eliminaram as formas públicas e democráticas de regulação. No próprio governo de Fernando Henrique Cardoso, a base de direitos da Consolidação das Leis do Trabalho (CLT) foi negociada e não protegida. 0 motivo, para a mesma pensadora, é de que havia uma dinâmica de reforma ${ }^{8}$ para remover entraves para a modernização e competitividade da indústria, à custa da exploração da classe trabalhadora, que passava por forte desemprego, informalidade e terceirização, à luz da reestruturação produtiva no país.

No entanto, pode-se dizer que a esfera pública composta pelos "de baixo" só ganhou um terreno de capilaridade após a elaboração da Constituição Cidadã de 1988, que em um efêmero momento produziu cidadania para àqueles tratados sob o manto da desigualdade. Só que a mesma proteção social dirigida aos grupos subalternos combinou-se com a crise nacional e com a ideologia propagada pelo ideário neoliberal, desembocando em contestações e lutas sociais rumo a uma sociedade mais igualitária, potente e ativa, ao derruir com a prerrogativa de que o povo brasileiro é estagnado e/ou frágil. Sobretudo, quando estes grupos coletivos presenciaram o avanço da democracia liberal, na visão de Wood (2010), a qual se ampara na defesa e primazia da propriedade privada, mercado e individualidade na atualidade, fazendo coexistir a igualdade política com a desigualdade de classe $^{9}$.

Como a sociedade civil, na perspectiva gramsciana que defende direção, hegemonia e consenso, mostrou uma potência ao responder e se organizar ante os ditames do neoliberalismo (OLIVEIRA, 1995), surgiram outras formas de organização popular mais institucionalizadas, como a construção de Fóruns Nacionais de Luta pela Moradia, pela Reforma Urbana, Fórum Nacional de Participação Popular etc (GOHN, 2003, p. 20). De alguma forma, estes espaços democráticos estabeleceram a prática de encontros nacionais, produzindo diagnósticos sobre as necessidades sociais, como a elaboração de metas e finalidades para enfrentá-las (GOHN, 2003).

Convenha-se que, mesmo sendo ocupados pelos movimentos sociais e ações coletivas, os espaços democráticos e de discussão dos direitos não deixavam de demonstrar o antagonismo de 
classe e denúncia das necessidades sociais da população espoliada e destituída de direitos, para a reprodução do capital. Se, por um lado, os protestos e manifestações deixaram de ter mais frequência nos logradouros e/ou espaços menos institucionalizados, por outro, este panorama demonstra que a organização e estruturação dos sujeitos se gestavam de outra forma, para contestar e lutar pela capilaridade dos direitos sociais, no limiar do regime neoliberal.

Assim, ante 0 ataque neoliberal aos direitos e a proteção social, no que concerne às condições de trabalho, moradia, serviços e políticas sociais, Gohn (2003, p. 21) assinala que foram emergindo outros movimentos sociais, como contra as reformas estatais, a Ação da Cidadania em oposição à fome, movimentos de desempregados, mobilizações de pensionistas da Previdência Social, além dos trabalhadores do setor de transportes alternativos ("perueiros") e os caminhoneiros. Vale a pena expressar que estes sujeitos coletivos emergiram como respostas à crise socioeconômica, atuando mais como grupos para pressionar o poder público do que como movimentos sociais estruturados. As ações e mobilizações pela paz, em antagonismo à violência urbana, são exemplos desta categoria mencionada (GOHN, 2003).

No mesmo cenário, merecem destaque outros grupos e movimentos sociais. 0 primeiro são os grupos de mulheres organizados no rol de 1990, em virtude de seu trabalho na política, produzindo redes de conscientização de seus direitos e frentes de lutas em oposição às discriminações ${ }^{10}$. 0 movimento dos homossexuais também recebeu impulso em relação às passeatas e atos de protestos. Ainda, surgiram as ações do movimento afro-brasileiro na luta pela constituição de identidade e contra a questão da discriminação racial (GOHN, 2003, p. 21).

Outros protagonistas são três movimentos importantes nesse período. 0 primeiro foi 0 movimento dos indígenas pela demarcação de suas terras e comercialização de seus produtos a preços justos. $O$ segundo, movimento dos funcionários públicos (com ênfase no âmbito da saúde e educação), se organizou em associações e sindicatos em antagonismo às reformas e ajustes fiscais. $E$, por último, se encontra o movimento dos ecologistas, momento em que emergiram várias ONGs (Organizações Não-Governamentais). Estas ONGs não agiam da mesma forma que as que existiam no ano de 1980 (na atuação com os movimentos populares e de direitos humanos) (GOHN, 2003, p. 21 22).

$\mathrm{Na}$ concepção da autora referida, na virada do novo milênio o perfil dos movimentos sociais muda, já que a conjuntura política se transformou. No entanto, tais sujeitos foram também coartífices desse novo cenário, pelo o que ele tinha de positivo, no sentido da conquista de novos direitos sociais, corolário das pressões e manifestações que eles - movimentos - realizaram no ano de 1980. Embora se tenham enfraquecido e desorganizado os movimentos em função das políticas 
neoliberais ${ }^{11}$, em 1990 os movimentos em geral e, até mesmo os populares, absorveram posições mais ativas/propositivas (GOHN, 2003, p. 30).

Anos mais tarde, ponderam Carvalho e Guerra (2015, p. 42) que em meados da segunda década do século XXI, no Brasil, perpassou-se por um novo tempo na civilização do capital em fase de crise, através da expansão conservadora, com o surgimento de novas direitas a manifestarem o ódio de classe. Desdobraram-se, com isso, a marcha da intolerância em âmbito mundial; o retorno com intensidade do neoliberalismo após a crise de 2007-200912, obrigando uma agenda política de ajuste aos Estados; expressões da luta de classes em um cenário de emergência de revoltas populares; mudanças e reviravoltas sociopolíticas e culturais, a colocar em jogo os partidos, governos e esquerdas.

Esses fatores, entretanto, não impediram as manifestações e mobilizações dos trabalhadores, já que no mês de junho no Brasil, no ano de 2013, os políticos, partidos, imprensa, cronistas políticos e cientistas sociais se surpreenderam pelas mobilizações de massa que transformaram a face e o cotidiano das cidades. Essas manifestações representam grandes e raros momentos da história, em que alterações e rompimentos que aparentavam inimagináveis se desenham na agenda política da sociedade. Afinal, são estes movimentos e dinâmicas que carregam para as cidades e para a esfera pública o frescor do que ainda não foi infectado pela ideologia neoliberal, ancorada no empreendedorismo, individualismo e competição. Os movimentos, assim, passam a enfrentar a cidade de exceção, a cidade-empresa e a democracia direta do capital, desejando uma outra cidade e outro espaço público (VAINER, 2013, p. 35-40).

Nessas lentes, no ano de 2020, no Brasil, com o decorrer do avanço da pandemia causada pelo COVID-1913, perceberam-se, segundo sites ${ }^{14}$ e meios midiáticos, diversas manifestações da população via panelaços, contra o governo de Jair Bolsonaro, presidente da república que tomou posse no dia primeiro de janeiro de dois mil e dezenove. O grito de resistência da classe trabalhadora que vivencia no seu cotidiano um conjunto de extorsões à vida para a preservação da propriedade privada, foi: "fora, Bolsonaro" e "impeachment", nas cidades de São Paulo, Rio de Janeiro e Belo Horizonte.

Nesse contexto de pandemia, Brettas (2020) realizou um questionamento sobre se há ou não uma oposição entre salvar vidas e salvar a economia, no decorrer do corrente governo. Uma vez que este impasse auxilia a decodificar o que a alienação obscurece: no modo de produção do capital, a produção da riqueza ocasiona incompatibilidades com a defesa à vida da maior parte dos grupos sociais. Neste sentido, "o discurso de ódio mobiliza e legitima o uso da violência para construir as 
bases de sustentação do avanço de pautas reacionárias e o aprofundamento das relações capitalistas" (BRETTAS, 2020, p. 12).

Tais nuances alertam para a possibilidade de permanência das ações coletivas e de resistência contra o avanço neoliberal, aos ataques de criminalização e de desqualificação dos sujeitos sociais difundidos pelo atual governo. Os discursos do presidente propagados no quadro de altas taxas de mortalidade ${ }^{15}$ - especialmente de pessoas oriundas das camadas empobrecidas, grávidas, idosos, políticos, artistas, residentes de comunidades e diversos tipos de profissionais que estão trabalhando na linha de frente contra o coronavírus - têm sido de profunda ameaça à sobrevivência e até mesmo aos princípios constitucionais respaldados na própria $\mathrm{CF} / 88$. As frases degradantes para os trabalhadores e brasileiros, relatadas pelo presidente Jair Bolsonaro, foram: "Eu não sou coveiro, tá?" e "Alguns vão morrer? Vão, ué, lamento. É a vida [...]".16

$\mathrm{Na}$ interpretação de Brettas (2020), precisa-se denunciar que a austeridade e 0 encurtamento de gastos nunca foram mecanismos benéficos para os trabalhadores. 0 cenário aponta para o aprofundamento da disputa acerca do fundo público, e uma etapa de enfrentamento é desmentir a prerrogativa de que não há recursos de cunho financeiro. Neste sentido, a primeira proposta é revogar a Emenda Constitucional 95 - que constitucionaliza o ajuste fiscal e delimita um teto para 0 investimento das políticas sociais -, responsável pela remoção de $\mathrm{R} \$ 22,48$ bilhões do Sistema Único de Saúde (SUS), entre os anos de 2018 e $2020^{17}$.

Agir dessa forma é negar uma parcela ou o todo da ordem capitalista, bem como agem os movimentos sociais, os sindicatos, os partidos de esquerda e outras formas de luta coletiva. Trata-se de enfrentar o ser serializado e sua consciência imediata, na grandeza em que o mesmo é convocado para a luta e ação, uma vez que os conflitos e consciência de classe são imprescindíveis para os trabalhadores, como já observou Marx. Nesta ocasião, importa dizer que a principal mediação que atuou e continua operando sobre a consciência reificada dos trabalhadores, após a rapidez do neoliberalismo, é a ideologia, que não permite enxergar a totalidade de forma articulada (IASI, 2013).

Roio (2007, p. 64) complementa que as lutas da classe trabalhadora pela hegemonia devem se espraiar para fora das fábricas e empresas, a partir da autonomia e da autoorganização, à revelia da classe dominante. Green $(2016$, p. 60$)$ investiga que com a ausência de um movimento revolucionário de massa, os grupos sociais dominantes usam os militares e a violência para resguardar suas posições e prevenir que os grupos sociais subalternos alcancem o poder político. Isso porque 0 Estado moderno se implanta sobre a unidade da força e do consenso, e, em cima disso, os movimentos revolucionários precisam de uma direção intelectual e moral antes mesmo da conquista do poder político. 
Nesse fluxo de análise, a direção intelectual e moral da classe subalterna se conjugam com a ideia de Dagnino (2004), a respeito da escolha entre dois divergentes projetos políticos na sociedade brasileira. Assim, o termo "confluência perversa", cunhado pela autora, expressa esses dois embates: o projeto neoliberal e o projeto democratizante e participativo. 0 primeiro projeto busca se legitimar pelos ajustes fiscais e ausência do Estado, no que concerne aos direitos e responsabilidades sociais, como preconizado no Consenso de Washington (1989). O segundo projeto, de cunho democrático e cidadão, visa maior controle social e participação da sociedade civil na esfera e nos espaços públicos, consagrando os princípios dispostos na Carta Magna, sob a ênfase do restabelecimento da democracia formal.

A partir dessa reflexão, cabe à classe subalterna decidir o projeto que melhor a representa em um determinado cenário político, econômico e social. A proposta é que os sujeitos possuam criticidade e "bom senso" ao eleger os representantes políticos, os quais tomarão os rumos e estratégias para a administração do país e, consequentemente, para a gestão pública. Esta última irá, de fato, interferir na esfera privada da vida. A escolha, não obstante, vislumbra um olhar coletivo ao considerar a vida em sociedade e as demandas que ela requer, como também a análise de totalidade que o Ser social é capaz de realizar. Esta consciência crítica das condições de existência da classe trabalhadora é um processo que depende da ação social ${ }^{18}$ e organização coletiva.

\section{CONCLUSÃO}

O debate em tela demonstrou que após o período ditatorial no Brasil, seguido pela reestruturação produtiva e absorção dos princípios preconizados no Consenso de Washington (1989), houve um novo acordo econômico comandado pelos representantes rentistas e agentes políticos de diminuição do atendimento das demandas sociais da classe trabalhadora, com o aprofundamento da globalização neoliberal, das contrarreformas estatais, mercantilização e privatização de todas as riquezas e bens produzidos. Este acordo, com ênfase na propriedade privada, instituiu uma das formas de fazer política no solo brasileiro: o retorno dos velhos mecanismos de regulação do Estado, com marcas do patrimonialismo, violências, injustiças sociais, expropriações, desmonte dos direitos e condições de trabalho, clientelismo e favorecimento de algumas classes em detrimento de outras.

A sociedade civil no sentindo gramsciano, não obstante, mostrou uma atitude ativa e propositiva frente ao quadro demonstrado do Brasil, especialmente durante e após a passagem depreciativa da ditadura. Neste sentido, foram as mobilizações e lutas que fizeram surgir os "novos sujeitos sociais", requerendo uma outra sociabilidade e pacto social com o Estado, baseado na 
democracia. Os movimentos sindicais, populares, do campo e estudantil aspiravam os direitos de cidadania, em oposição aos pressupostos da modernização conservadora, da expropriação dos grupos subalternos da cidade e de sua participação social e política. Não foi à toa que surgiu a CF/88 representando os anseios destes grupos sociais por democracia e qualidade de vida.

Observou-se, a partir do avanço neoliberal no país e as estratégias econômicas baseadas na austeridade fiscal, que as ações coletivas e mobilizações sofreram um momento de ausência de estruturação e organização nas ruas, em face da destruição dos serviços e políticas sociais, de tal modo que era um entrave para a constituição de coletividade e unidade entre a classe trabalhadora. 0 projeto de desenvolvimento do país se revelou a favor da esfera privada e do capital volátil, o que depreciou o projeto social ligado ao sistema de garantia de direitos via ações estatais.

Válido rememorar que esse período foi palco da derrocada do Muro de Berlim na Alemanha, com o término da Guerra Fria (1989). A partir disso, com a liderança do sistema capitalista como modo de produção ocorreu a desmobilização das lutas na órbita mundial. No entanto, isso foi por pouco tempo, já que os sujeitos sociais protagonizaram outros modos de organização, especialmente na esfera mais institucionalizada como Fóruns, Conferências e Congressos, como ocorreu no caso brasileiro. Tais espaços públicos permitiram os encontros e elaboração de demandas para a negociação com o Estado, representado, ainda, pelos interesses hegemônicos.

O que se tem presenciado na contemporaneidade não é o desmantelamento da organicidade e potencialidade dos trabalhadores, uma vez que existem outros canais além de logradouros públicos e institucionais para se fazer política e protestos contra o ódio de classe, difundido na atualidade. As denúncias das condições de espoliação do cotidiano são marcadas pelo sentido de continuar atuando em outras frentes de pesquisas, projetos, mercado de trabalho e de participação nos espaços públicos de direitos, como muitos profissionais, estudantes e pesquisadores realizam. Isso é exemplificado, por meio de Maricato (2003, p. 22), pela luta e enfrentamento de diversos sujeitos para a produção de um novo quadro jurídico e institucional relativo às cidades, o que resultou no Ministério das Cidades (2003), Estatuto da Cidade (2001) e Conselhos e Conferências Nacionais da Cidade $(2003,2004,2005$ e 2007).

Espera-se, portanto, que os conflitos e as lutas sociais possam ressignificar os cotidianos marcados pela violência institucional e autoritarismos, especialmente em cada postura de governo. A intenção é que as ações coletivas possam se articular e se organizar em várias esferas de direitos sociais, como forma de defender a cidadania, destronar os espaços públicos privatizados e até mesmo ter acesso à cidade, com possibilidade de exercer a autonomia e liberdade, denunciar a criminalização e desqualificação dos discursos e ações conservadoras atuais. 


\section{REFERÊNCIAS}

ANTUNES, R. Adeus ao trabalho?: ensaio sobre as metamorfoses e a centralidade do mundo do trabalho. 14. ed. São Paulo, Cortez, 2010.

BEHRING, E. R. Brasil em contra-reforma: desestruturação do Estado e perda de direitos. 2. ed. São Paulo: Cortez, 2008.

Crise do capital, fundo público e valor. In: BEHRING, E. et al (org.). Capitalismo em crise, política social e direitos. São Paulo: Cortez Editora, 2010.

.; BOSCHETTI, I. Política Social: Fundamentos e História. São Paulo: Cortez Editora, 2011.

BRETTAS, T. Defender a vida é preciso, a economia não. In: MOREIRA, E. et al. (orgs.). Em tempos de pandemia: propostas para defesa da vida e de direitos sociais. Rio de Janeiro: UFRJ, Centro de Filosofia e Ciências Humanas, Escola de Serviço Social, 2020.

CARVALHO, A. M. P. de; GUERRA, E. C. O Brasil no século XXI nos circuitos da crise do capital: 0 modelo brasileiro de ajuste no foco da crítica. Revista Pol. Públ., São Luís, v. 19, n. 1, p. 41-60, 2015.

COUTINHO, C. N. O Estado brasileiro: gênese, crise e alternativas. In: LIMA, J. C. F.; NEVES, L. M. W. (orgs.). Fundamentos da educação escolar do Brasil contemporâneo. Rio de Janeiro: Fiocruz, EPSJV, 2006.

DAGNINO, E. Construção democrática, neoliberalismo e participação: os dilemas da confluência perversa. Política e sociedade, n. 5, p. 139-164, 2004.

DURIGUETTO, M. L.; MONTAÑO, C. Estado, classe e movimento social. São Paulo: Cortez, 2011, v. 5. (Biblioteca Básica do Serviço Social).

FACHIN, Z. A.; PAGLIARINI, A. C. Movimentos Sociais na Constituição Brasileira de 1988: A Construção da Democracia e dos Direitos Humanos. Direitos Humanos e Democracia: Editora Unijuí, ano VI, n 12, 2018.

GOHN, M. da G. 500 anos de lutas sociais no Brasil: movimentos sociais, ONGs e terceiro setor. Rev. Mediações, Londrina, v. 5, n. 1, p. 11-40, jan.jun. 2000.

. Movimentos sociais na atualidade: manifestações e categorias analíticas. In: GOHN, Maria da Glória (org.). Movimentos sociais no início do século XXI: antigos e novos atores sociais. Rio de Janeiro: Vozes, 2003.

Teoria dos Movimentos Sociais: paradigmas clássicos e contemporâneos. São Paulo: Edições Loyola, 1997.

GREEN, M. E. Gramsci e as lutas subalternas hoje: espontaneidade e organização política. Revista Outubro, n. 25, p. 53-81, mar. 2016. 
IASI, M. L. A rebelião, a cidade e a consciência. In: MARICATO, E. et al. (org.). Cidades Rebeldes: Passe Livre e as manifestações que tomaram as ruas do Brasil. 1. ed. São Paulo: Boitempo, Carta Maior, 2013.

LÖWY, M. A teoria do desenvolvimento desigual e combinado. Actuel Marx, 18, p. 73-80, out./1995.

MARICATO, E. É a questão urbana, estúpido! In: MARICATO, E. et al. (org.). Cidades Rebeldes: Passe Livre e as manifestações que tomaram as ruas do Brasil. 1. ed. São Paulo: Boitempo, Carta Maior, 2013.

MARSHALL, T. H. Cidadania, classe social e status. RJ: Ed. Zahar, cap. 3 (p. 57-114), 1967.

NETTO, J. P. Ditadura e Serviço Social: uma análise do Serviço Social no Brasil pós-64. 16. ed. São Paulo: Cortez, 2011.

OLIVEIRA, F. de. Neoliberalismo à brasileira. In: SADER, E.; GENTILI, P. (orgs.). Pós-neoliberalismo: as políticas sociais e o Estado Democrático. Rio de Janeiro: Paz e Terra, 1995.

PEREIRA, P. A. P. Política Social do Segundo Pós-Guerra: Ascensão e Declínio. Revista Serviço Social \& Saúde, UNICAMP Campinas, n. 10, 2010.

RAICHELIS, R. Esfera pública e Conselhos de Assistência Social: caminhos da construção democrática. 2. ed. São Paulo: Cortez, 2000. Gestão Pública e a Questão Social na Grande Cidade. Lua Nova, São Paulo, p. 13-48, 2006.

RIBEIRO, A. C. T. Cartografia da ação social, região latino-americana e novo desenvolvimento urbano. In: POGGIESE, H.; EGLER, T. T. C. (org.). Otro desarrollo urbano: ciudad incluyente, justicia social y gestión democratica. Buenos Aires: Clacso, p. 147-156, 2009.

ROIO, M. D. Gramsci e a emancipação do subalterno. Rev. Sociol. Polít., Curitiba, 29, p. 63-78, nov. 2007.

SADER, E. Quando novos personagens entraram em cena: experiências, falas e luta dos trabalhadores da Grande São Paulo, 1970-80. 4 ed. Rio de Janeiro: Paz e Terra, 2001.

SIMIONATTO, I. Classes subalternas, lutas de classe e hegemonia: uma abordagem gramsciana. Rev. Katál., Florianópolis, v. 12, n. 1, p. 41-49, jan.jun. 2009.

TELLES, V. da S. Sociedade civil e os caminhos (incertos) da Cidadania. São Paulo em Perspectiva, p. 07-14, 1994.

VAINER, C. Quando a cidade vai às ruas. In: MARICATO, E. et al. (org.). Cidades Rebeldes: Passe Livre e as manifestações que tomaram as ruas do Brasil. 1. ed. São Paulo: Boitempo, Carta Maior, 2013.

WOOD, E. M. O demos versus "nós, o povo": das antigas às modernas concepções de cidadania. In: Democracia contra capitalismo. SP: Boitempo, p. 177-204, 2010. 


\section{Notas}

1 Gohn (2000, p. 13) pontua que os movimentos sociais são ações coletivas de caráter sociopolítico, compostos por sujeitos que provêm de divergentes classes e camadas sociais. Ainda, eles partilham uma identidade em comum e passam a defender projetos e demandas.

2 Refere-se a uma visão fragmentada do real, que também se relaciona a uma forma de cultura (SIMIONATTO, 2009).

${ }^{3}$ Raichelis (2006) expressa que a questão social é a manifestação das desigualdades sociais construídas e reproduzidas no movimento antagônico das relações sociais e, na dinâmica contemporânea, por meio das configurações assumidas pelo trabalho e pelo Estado, na fase mundializada do capital. Salienta-se que sua reprodução, formas de permanência e metamorfoses devem ser compreendidas através das novas configurações e mediações sociopolíticas - no âmbito nacional e internacional - próprias da sociedade atual.

4 Produziu uma massa de trabalhadores desqualificados e precarizados, presenciando formas de part-time, emprego temporário, parcial, ou então vivenciando o desemprego estrutural (ANTUNES, 2010).

5 Em consonância com Duriguetto e Montaño (2011), os novos movimentos sociais emergiram no ano de 1960-1979, sendo um complemento das lutas dos movimentos conhecidos como "clássicos" (como os sindicatos e partidos). Os novos movimentos sociais possuem identidade, pertencimento, demandas, se estendendo às mobilizações por questões ecológicas, de gênero, de orientação sexual, por direitos civis e religiosos, por educação e moradia, entre outros. Válido proferir, para os autores, que um acontecimento importante para a gênese de outras lutas sociais foi o Maio Francês (1968) ocorrido na França, marcado por lutas e greves, respectivamente de estudantes e operários, em antagonismo à desigualdade e repressão.

6 Para Fachin e Pagliarini (2018, p. 153), os movimentos sociais tiveram um papel no processo constituinte de 1987-1988 e na consolidação da democracia, seja pela luta dos clubes de mães, movimentos de moradores de periferias, comunidades eclesiais de base, movimentos do custo de vida, movimentos em oposição à carestia, pelo emprego, entre outros. 0 pano de fundo gerado por suas mobilizações pode ser encontrado nos artigos $6^{\circ}$ ao $11^{\circ}$ da CF/88, que incorpora os "Direitos Sociais".

70 país até 0 ano de 1930 era uma formação político-social do tipo "oriental", o Estado era tudo e a sociedade civil era percebida como primitiva. Reside na mesma ideia, a tônica de que o Brasil foi um Estado antes de ser uma nação, no mesmo momento em que se excluíam os setores subalternos de qualquer decisão política (COUTINHO, 2006).

8 Na era de Fernando Henrique Cardoso (FHC) tratou-se de "reformas" norteadas para mercado, em uma conjuntura em que os problemas do Estado brasileiro eram sinalados como causas fundamentais da aguda crise econômica e social, alastrada desde 0 ano de 1980. Decerto era um termo destituído de seu caráter redistributivo de viés social-democrata, já que a concepção se relacionou a uma estratégia político-ideológica para a procura de consensos e legitimidade, com 0 objetivo de resguardar a direção intelectual e moral da hegemonia neoliberal (BEHRING; BOSCHETTI, 2011).

${ }^{9}$ Essa atitude foi explorada por Marshall (1967), que dizia que a desigualdade entre classes sociais poderia ser aceitável desde que a igualdade de cidadania pudesse ser reconhecida. No século XX, por exemplo, com a luta de classes pelos direitos sociais, observou-se a efetivação do Estado de bens e serviços para aqueles que precisavam, especialmente nos "Anos de Ouro" conhecido como Estado de Bem-Estar Social.

10 De acordo com Gohn (1997), a luta das mulheres, dos ecologistas, dos negros e dos índios recebeu notoriedade nesta época, mas já eram lutas antigas desde o final de 1970, no solo brasileiro.

11 Vale pontuar que os efeitos da globalização, sobretudo no ano de 1990, vão se amparar em duas perspectivas básicas: a cidadania coletiva e a expropriação. A primeira, já aludida na década anterior, não se trata somente de reivindicar e pressionar o poder público, mas de ter uma participação qualificada. A segunda, referente à expropriação, provém das condições socioeconômicas, como a violência, desagregação da autoridade estatal, emergência de estruturas de poder paralelas, entre outras. Tais fatores vão recair sobre a classe trabalhadora, onde os sindicatos perderão espaço, devido às condições difíceis de organização no setor de economia de caráter informal. Pode-se afirmar que a crise econômica levou a um decréscimo dos empregos na economia formal e ainda a extensão da jornada mais longa de trabalho, o que fez remover 
o tempo disponível dos sujeitos para 0 ato de mobilização, além dos movimentos populares progressistas terem perdido 0 apoio irrestrito da Igreja católica, em relação à Teologia da Libertação ao longo do ano de 1970 a 1980 (GOHN, 1997).

12 Conforme apregoa Behring (2010), este período se compara à crise do ano de 1930, tendo origem nos empréstimos hipotecários norte-americanos.

${ }^{13}$ Para o Ministério da Saúde, "a COVID-19 é uma doença causada pelo coronavírus SARS-CoV-2, que apresenta um quadro clínico que varia de infecções assintomáticas a quadros respiratórios graves" (Disponível em: https://coronavirus.saude.gov.br/sobre-a-doenca. Acesso em: 19 maio 2020).

${ }^{14}$ Disponivel em: https://g1.globo.com/politica/noticia/2020/03/25/cidades-brasileiras-registram-panelacos-contra-bolsonaropelo-nono-dia-seguido.ghtml. Acesso em: 19 maio 2020.

${ }^{15}$ Segundo site do Ministério da Saúde, o Brasil possui mais de 17.971 casos de óbitos confirmados, taxa de letalidade em 6,6\% e mortalidade em 8,6 (Disponível em: https://covid. saude.gov.brl. Acesso em: 19 maio 2020).

${ }^{16}$ Consultar: https://jornaldebrasilia.com.br/politica-e-poder/25-perolas-de-bolsonaro-sobre-a-pandemia-e-contando/. Acesso em: 19 maio 2020.

17 Disponivel em: http://www.epsjv.fiocruz.br/noticias/reportagem/a-importancia-de-um-sistema-de-saude-publico-euniversal-no-enfrentamento-a. Acesso realizado em: 14/04/2020 (BRETTAS, 2020, p. 17).

18 Segundo Ribeiro (2009, p. 154), a ação social se refere à autonomia dos sujeitos sociais e/ou a luta por alcançá-la, o que integra o controle dos sentidos da ação e a defesa de projetos que visa ultrapassar o meramente já dado. 